Draft: September, 2005

\title{
The Influence of the U.S. News and World Report Collegiate Rankings on the Matriculation Decision of High-Ability Students: $1995-2004^{*}$
}

\author{
Amanda Griffith \\ Department of Economics \\ Cornell University \\ Ithaca, NY 14850 \\ Alg53@Cornell.Edu \\ Kevin Rask \\ Professor of Economics \\ Colgate University \\ Dept. of Economics \\ Hamilton, NY 13346 \\ $\mathrm{Ph}: 315.228 .7524$ \\ KRask@,Colgate.Edu
}

\begin{abstract}
The annual U.S. News and World Report (USNWR) Guide to America's Best Colleges is a much anticipated magazine among both high-ability prospective students and college and university administrators. In this paper we use a decade of Colgate University Admitted Student Questionnaire surveys to estimate the influence of changes in a school's USNWR rank on the probability of matriculation of high-ability students. We find that the school choice of students is more responsive to changes in rank the higher (better) a school is ranked. This sensitivity to rank is independent of other objective measures of quality. As a group, women (aided and fullpay) are slightly less sensitive to the rankings than men, minorities (full-pay) are less sensitive to the rankings than non-minorities, and the rankings themselves have become more important over time for aided students. In terms of financial factors, the net cost of attendance along with the packaging of the aid matters for aided students. Finally, merit aid in general does not appear to influence high-ability full-pay students. Our results suggest that it is rational for college administrators (especially those at the highest ranked institutions) to pay attention to their USNWR rank because it is an important influence in yielding accepted students.
\end{abstract}

JEL Codes: I2, I21, I22

Keywords: School Choice, Student Financial Aid, Demand for Schooling

* We would like to thank Boris Zvetkov for able research assistance and Jill Tiefenthaler, Bob Turner, Mary Hill, Gary Ross for helpful discussions, and Larry Singell and two anonymous referees for insightful comments. 


\section{Introduction}

Every fall college administrators await the arrival of the U.S. News and World Report (USNWR) annual guide entitled America's Best Colleges. In it they are able to find out where USNWR ranks their school against the schools for which they compete for talented high school students. Administrators are caught between not wanting to place public emphasis on their ranking (-how can a college experience be represented by a single number?) and privately making sure that they don't slip in the rankings because studies have shown that applicant pools change when a school drops in the rankings. In response to changes in a school's rank, real resources are allocated and re-allocated so that particular characteristics of a school, studentfaculty ratio for example, can be improved in the hope that it will raise a school's overall rank. While the components and methodology behind the USNWR rank change periodically, the ranking itself has been in existence since the early 1980s when it began as a simple 'reputation' rank voted upon by college presidents. It has evolved since then to become a much more datadriven overall rank; however, the reputation component of the rank is still one of the most important of the individual components. Currently schools must fill out a questionnaire that provides the supporting data behind the USNWR collegiate rankings. In the most recent reporting year (2005) this questionnaire numbered a staggering 598 questions.

On the consumer side, high-ability high school seniors also await the arrival of this annual issue because it serves as a guide to the schools that they are considering for college. There is plenty of popular press that suggests the importance of the annual rankings, not least of which is the significant spike in circulation that occurs with this particular issue. Admissions officers attest to the importance, noting how many prospective students carry the issue to their college visits. They also feel that they are recruiting against their rank (if they are not in the top few in either major category) for the best and the brightest high school seniors. There is a broad literature evaluating the matriculation decisions of high school graduates. One strand of this literature looks at the general decision of whether or not to attend college, but that is a different population than the one studied here. Decisions of high-ability students about where to attend college has been less well studied. The existing literature generally models the decision as a combination of individual characteristics and school characteristics. These usually include some measure of school selectivity and various measures of the school environment itself, including 
financial cost and aid packaging. Given how long the USNWR rankings have been in existence and how influential they appear to be to both administrators and applicants, it is somewhat surprising that we have so little empirical evidence about their influence on the choices of these

high-ability students. This study provides information on those choices by estimating a discrete choice model of college matriculation, conditional upon a student being accepted, as a function of characteristics of the applicant and characteristics of the school, including the school's USNWR rank. We find that the USNWR rank is very important in the decisions that many highability students make about where to attend college. The paper proceeds as follows. Section 2 contains a review of the literature and is followed in Section 3 by a description of the data and methodology used in this study. Section 4 discusses our results in detail, and their implications for administrators of selective colleges and universities. In Section 5 we conclude.

\section{Literature}

To determine the relative importance of financial aid and non-monetary factors in students' matriculation decisions, Weiler (1996) used data from the College Board's Admitted Student Questionnaire Plus for students entering college in the fall of 1993. A Nested Multinomial Logit model was used to analyze the importance of both monetary and non-monetary variables in school choice, and more specifically the relative importance of the non-monetary characteristics of a school, such as academic reputation, compared to financial aid packaging characteristics. His results suggest that although the amount and make-up of financial aid packages is important in determining college choice, they are relatively less important than other, non-monetary, factors. Therefore, the specific attributes of colleges, such as student to faculty ratio and academic reputation, are very important to the decision making process for students when choosing a college.

Although Weiler found that monetary characteristics are relatively less important in school choice for students, it has been shown in other studies that financial aid characteristics do indeed have importance in the matriculation decision. Earlier work in this area, including Ehrenberg and Sherman (1984), Moore, Studenmund, and Slobko (1991), and McPherson and Schapiro (1991), established the importance of financial aid level and packaging on the matriculation decision. However, while the former two studies are micro evaluations of the individual choice to enroll at a particular institution, the latter is an aggregate (albeit disaggregated to different 
groups) investigation of enrollment trends and net costs across groups. Parker and Summers (1993) also estimate an aggregate model of matriculation rates and college costs at a sample of liberal arts colleges. As one of a set of selectivity controls, their specification contains a dummy variable for whether the school is in the top 25 of the USNWR rankings. They find the expected sign but inefficient estimates for their full-pay sample and a negative and significant estimate in their aided sample (implying that better ranks lead to higher matriculation rates). Unfortunately their sample sizes are small so it is unclear whether the inefficient estimates are a consequence of no influence or simply too much collinearity with other selectivity measures in their equation. Even earlier manuscripts by Spies (1973, 1978), based upon a set of surveys looking at the application decisions of above-average ability students, found that academic considerations generally outweighed financial considerations in the choice of where to apply. These surveys pre-dated the USNWR; however, his findings of the importance of the academic reputation of the school are in line with ours, with academic reputation here being measured by the USNWR ranking.

Most recently Avery and Hoxby (2003) modeled how students respond to different components of financial aid packages; grants, loans and work-study. High-aptitude seniors applying to enter college in 1999 were surveyed to obtain data on financial aid packaging of the schools to which each student was accepted. Increased grants, loans and work-study from a school made a student more likely to attend. To the authors' surprise, students responded more strongly to increased work-study than to either loans or grants. As expected, students from lowincome families responded more strongly to higher grants than did students from high-income families. Avery and Hoxby also looked at the selectivity of each school within a student's choice set. While students were more likely to attend the most selective school in their choice set, those from high-income families were more sensitive to the selectivity of the school. Several other variables examined were found to have no significant effect on school choice: distance from home, whether or not the student went to a private high school and whether the college was located in the student's home state. Our results support theirs in finding no influence of the distance to the college and type of high school for aided students. Another interesting result of the Avery and Hoxby study was how students respond to merit scholarships, or grants with specific names. Students, especially those from low-income families, responded more strongly in their collegiate choice decision to grants awarded for merit and those with names. In this area 
our results differ; however, because our data on aid packaging is not as detailed as theirs. Therefore our results are not directly comparable to theirs.

USNWR rankings, while likely affecting students' choices in matriculation, also seem to have an effect on financial aid offerings from schools. Monks and Ehrenberg (1999) used aggregate data and showed that an increase in ranking number (drop in rank) for a school leads to increased total financial aid, presumably to attract more students. They also found that this drop in rank led to a higher admit rate, and therefore a drop in selectivity. Their findings that a drop in the rank lowers the yield rate for that school are of particular interest here. Our model is a micro version of the matriculation decision of accepted students (yield from the perspective of the school). Our estimates for aided students are similar, but for full-pays are larger in magnitude than theirs; however, the most important difference pertains to our results that the influence of the rankings changes as your school moves down the rank scale.

Our study builds upon the existing literature by estimating a broader micro-model of matriculation (modeling the choice among many possible institutions) that explicitly accounts for a school's USNWR ranking, cost, other measures of quality and prestige, and finally includes fixed effects for a broad set of elite schools historically ranked in the top 40 in either the National University (NU) or National Liberal Arts category (NLA). Past studies have suggested that measures of selectivity and cost are important but that the school selectivity effect dominates. School selectivity has been measured in the literature in different ways, but not in a micro-model along with the USNWR rank itself. The USNWR rank is a combination of many of the accepted measures of selectivity (average SAT, admit rate); however, it is a single, prominent characteristic that high school seniors readily remember ${ }^{1}$. Many of the individual components of the overall USNWR rank can differ significantly across schools. For example, in the 2003 Liberal Arts rankings Carleton ranked $12^{\text {th }}$ in graduation/retention and $13^{\text {th }}$ in selectivity but tied for $4^{\text {th }}$ overall. Wellesley, who was also tied for $4^{\text {th }}$ in the Liberal Arts category, was ranked $22^{\text {nd }}$ in selectivity and $27^{\text {th }}$ in faculty resources. Similar comparisons can be made in the National University group, where MIT ranked $9^{\text {th }}$ in graduation/retention and $11^{\text {th }}$ in faculty resources but stood $4^{\text {th }}$ in the overall ranking. While there are different ways to measure selectivity and

\footnotetext{
${ }^{1}$ The final USNWR rank is a weighted combination of 7 main groups of measures from each school. It should be noted that these weights do not correspond closely to the 'net' impact of changes in any particular category on the final rank. These issues are discussed more fully in Webster (2001a, b) and Friedman and Rask (2004). The detailed ranking methodology along with the weights can be found at www.USNews.com.
} 
different ways to measure retention and graduation performance, we believe the overall rank is what exerts the influence in the matriculation decision. In addition, we believe an important component of the 'school selectivity' results found in the literature is in fact the influence of the USNWR rank. In addition to explicitly modeling the influence of school rank we also exploit the panel attributes of the data to test whether the rankings themselves have become more or less important over the past decade. Finally, we investigate whether changes in rank matter more for lower vs. higher ranked schools and whether rank is more or less important to lower vs. higher high-ability students.

The USNWR rank having an influence on the matriculation decision has important implications for resource allocation in the market for higher education. Administrators that reallocate resources in an attempt to maximize their rank can do so without improving the academic quality of their school. If a school is being operated relatively efficiently, these reallocations will likely lower the actual quality of the education being delivered. There is also the possibility that too much emphasis on a school's rank will cause student 'mismatch' in the market for higher education. In this scenario a student matriculates to a school that is worse along dimensions they feel are important because they are influenced by the overall USNWR rank of that school. A formal analysis of matching in this market is beyond the scope of this paper but is an interesting issue for future research.

\section{Data and Methodology}

Data for this study were obtained from the Colgate Admitted Student Questionnaires (ASQ) for the students entering in the fall of 1995 through the fall of 2004. This questionnaire is sent in the spring of their high school senior year to all admitted students. Roughly $50 \%$ of the admitted students return the questionnaire in any given year $(\approx 1,200)$ with the response rate skewed towards those choosing to attend Colgate ${ }^{2}$. Among the many questions pertaining to their evaluation of various schools, students are asked to list the top three college choices to which they were admitted. In addition to this, they are asked to list what types of financial aid, if any, they received from each of these schools. Students are also asked for socioeconomic information, such as parental income range, ethnicity/race, gender and the type of secondary

\footnotetext{
${ }^{2}$ We don't believe this is an important source of response bias because we are modeling choice among a set of schools, not simply whether they choose to attend Colgate or not. We have a large sample of students who went elsewhere, both to higher and lower ranked schools.
} 
school attended. Data on academic ability (SAT scores), financial aid, and parental income are added from Colgate institutional records. Characteristics of the schools in the choice set were obtained from the Integrated Postsecondary Education Data System (IPEDS) ${ }^{3}$ files maintained by the National Center for Education Statistics and from the Annual Survey of Colleges undertaken by the College Board. Finally, past issues of the USNWR are the source for the rankings of each school in each student's choice set. The rankings contained in the fall issue prior to the spring matriculation decision are used.

In this study students are split into two groups, aided and full-pay. Given the importance of financial considerations for aided students, the differences in their packaging, and the extra information available on parental income for aided students, we chose to estimate full-pays separate from aided students ${ }^{4}$. Our definition of an aided student is anyone who applied for and was offered need-based aid from any institution to which they were admitted. Unfortunately financial aid information in the ASQ is limited to whether their package contained any of four distinct components, need-based grant, non-need based grant (merit aid), loan and work-study. All of these variables are reported in the ASQ as binary, indicating whether or not a student received each component, but not the amount of each type of aid given by each school. For a more parsimonious specification all the possible combinations of aid packaging are combined into four primary groups ${ }^{5}$. The first group is grant or merit aid only, the second grant/merit plus any combination of job and loan, the third is only job and loan (no grant or merit) and the final (omitted) category is no aid package at all. Many $(3,071$ of the 12,502$)$ student/school combinations were offered need-based aid from at least one school but were not offered any need-based aid from another school. We use this combination as our omitted category for the aid packaging control variables. A shortcoming of these data is that detailed financial aid amounts from each school are not known. To somewhat overcome this data limitation we construct a measure of net cost of each school from Colgate administrative records and IPEDs tuition, room, and board data ${ }^{6}$. From institutional records we know each students financial contribution based

\footnotetext{
${ }^{3}$ http://nces.ed.gov/ipeds/

${ }^{4}$ Pooling the two groups was rejected with a LR test statistic of $\chi_{23}^{2}=424$.

${ }^{5}$ Initially grants and merit-aid were separated; however, there was no statistical difference between their influences so they are combined.

${ }^{6}$ Roughly $4 \%$ of schools had missing cost data at some point during the sample. In these cases we used simple OLS to estimate their cost in the missing year based upon their costs in the remaining years in the sample.
} 
upon two different formulae, Colgate institutional methodology (IM, based largely upon the College Board's Institutional Methodology) and the federal methodology (FM). In our model the family contribution, as long as it is less than the tuition, room, and board, constitutes the net cost of attendance. If the sum of tuition, room, and board is less than family contribution, we use that as the net cost of attendance. For the full-pay sample the net cost is measured as the sum of tuition, room, and board ${ }^{7}$. We know the exact net cost from Colgate, however, we do not observe the exact net cost from the other schools in the data (-because we lack their exact calculation of family contribution). Therefore we construct two measures of net cost, one based upon Colgate's $I M$ and one based upon the FM. The results are not statistically different from one another at conventional levels of confidence so we use the $I M$ version of net cost for the following reason ${ }^{8}$. Many schools in this sample are members of the 568 Group, a group of schools who adopt a consistent financial aid methodology called the consensus methodology ${ }^{9}$. That methodology is quite similar to the IM used at Colgate, however there are slight differences in how student assets are treated and how home equity is treated. In some cases Colgate applicants get slightly more favorable treatment under $I M$, in some cases less favorable, however, it shouldn't systematically bias the results because some schools are ranked above us and some below. Most other schools in the sample use the $I M$ as their basis for determining need, even though there are always subjective decisions being made in particular cases. Given the measurement error in our net cost for schools other than Colgate we are confident in the order of magnitude of our results but they can't be interpreted as finely as those reported in Avery and Hoxby (2003), for example.

Personal characteristics of each student are also included in the model. These characteristics are used to determine whether students from different socioeconomic backgrounds or students with different academic ability have different sensitivities to the USNWR rankings, to cost, or to distance from the school. We also test for gender or minority differences in responsiveness to rank along with the influence of the proportion of minorities at each school on the matriculation choice of minorities. Finally, school fixed effects are included in our model. They allow us to control for unchanging characteristics (quality, prestige, name-recognition) that certain schools

\footnotetext{
${ }^{7}$ All net cost amounts are calculated in constant 2005 dollars.

${ }^{8}$ The estimates (and SEs) for the two models are: $\hat{\beta}_{\text {InCost }}^{I M}=-.129(.032) \hat{\beta}_{\text {InCost }}^{F M}=-.108(.033)$

9 The consensus methodology and the member institutions can be found at http://www.568group.org.
} 
possess. We include dummy variables for most all of the schools whose USNWR rank has averaged 40 or better in the NU and NLA category. Some schools in this group do not appear in the estimates because they were not in enough choice sets in our sample to estimate a separate fixed effect. The addition of these fixed effects assures that our USNWR measure is picking up the influence of the rank itself and is not confounded with unchanging institutional characteristics such as prestige.

In addition to different responses based upon individual characteristics our data allow the modeling of heterogeneity in responses to changes in the USNWR rankings across the USNWR ranking distribution. For example, does a school dropping from 1 to 3 in the rankings change a student's probability of making them their college choice in the same way that a drop from 10 to 12 would? Schools near the top of the rankings do not move much over time, and not nearly as much as schools that move around in the 15-30 range of the rankings. Our data allow us to test the hypothesis that changes in rank for a school in the lower (worse) end of the distribution have a different impact on student matriculation decisions than changes in the higher (better) end of the rank distribution.

\subsection{Descriptive Statistics}

The financially needy sample consists of 12,502 potential school choices made by 4,745 individuals. Most respondents listed their top three choices, some just listed top 2, and anyone listing only 1 school was eliminated prior to estimation. The full-pay sample is somewhat smaller, with 3,847 individuals yielding 10,251 ranked college choices. Over eighty percent of the first choice schools are ranked in the top 25 for either the NU or NLA categories by USNWR. One of the most interesting statistics that highlights the importance of the USNWR ranking is that every year, $50-55 \%$ of the students in the sample choose to attend the highest ranked school to which they were admitted (independent of whether it is categorized as a NLA or NU). Given that schools differ substantially along many of the components of the rankings, this strikes us as a very large proportion selecting the school with the highest overall USNWR rank and suggests how important the rankings themselves are in the matriculation decisions of this sample of students.

The set of Colgate ASQ information provides a good window into the decision-making process of a wide range of high-ability students. Our applicant pool overlaps with both top 25 
liberal arts colleges and liberal arts colleges ranked below $25^{\text {th }}$. Because Colgate's average rank over the past decade has been 18, we admit students using Colgate as a 'safety school' who prefer to go to a top 10 school along with those who are 'reaching' for admission to a school in the top 20. Colgate's size (approximately 2,800) puts it at the large end of most liberal arts schools, so in addition to overlap with other liberal arts colleges, the Colgate applicant pool has significant overlap with smaller private universities (such as those in the Ivy League) and midsized selective private universities (such as Notre Dame, Georgetown, Washington University in St. Louis, and Emory). Colgate also has a Division I athletics program that attracts students (and athletes) who are considering other large universities with Division I programs. In terms of the overall distribution of schools in the student responses, $16 \%$ are ranked in the top $15,37 \%$ in the 16-20 range (the group dominated by the Colgate responses), $13 \%$ in the $21-25$ range, and the remaining 34\% ranked below 25 . These proportions are across all the college categories in the rankings. The proportion of NLA (62\%) outweighs the proportion of NU (32\%) in the sample, but this is expected because Colgate is a part of the NLA category. These characteristics insure that a broad range of school types and USNWR rankings are common in the Colgate pool of ASQ responses. More detailed student and school descriptive statistics are contained in Table 1.

$* * * * * * * * * * * * * * * * * * * * * * * \quad$ Include Table 1 Here

As expected the respondents are more likely to be female and the aided sample is much more diverse than the full pay. The range of high-ability applicants to Colgate is evident in the combined SAT distribution where the $75^{\text {th }}$ percentile is over 1400 and the $25^{\text {th }}$ percentile is under 1300. Finally, the most common types of schools in the choice sets are somewhat different between the aided and full-pay students. The full-pay sample has more small and medium-sized private schools while the aided sample has higher frequencies of larger, regional universities (e.g. SUNY schools, Rochester, Syracuse).

\subsection{Empirical Model}

The data described above is used to estimate a model of collegiate choice where characteristics of the college and characteristics of the student are allowed to influence the observed school choice. The behavioral model underlying the empirical estimation strategy is a 
standard random utility model where the utility of the $i^{\text {th }}$ college to which the $\mathrm{j}^{\text {th }}$ student is admitted is a function of the characteristics of that school along with the characteristics of the particular student. Equation 1 outlines this general structure.

$$
U_{i j}=\alpha X_{j}+\beta Z_{i j}+\varepsilon_{i j}
$$

Some of the school characteristics are fixed across students (USNWR rank, student-faculty ratio, expenditures per student, and size) and their influence is estimated by the $\alpha$ 's. Others are variable across the students themselves (financial aid package, net cost, distance from home) and some are student-invariant characteristics (SATs, race, gender) that enter the model as interactions with particular school characteristics. These student-specific effects are measured by the $\beta$ 's. Finally, the collection of school fixed effects are measured by the $\gamma^{\text {'s }}$ in the model. Equation 2 represents the empirical formulation of the random utility model for the financial aid sample.

$$
\begin{aligned}
& \text { Choice }_{i j}=\alpha_{1} U S N W R_{i}+\alpha_{2} U S N W R_{i}^{2}+\alpha_{3} \text { Size }_{i} \\
& +\alpha_{4} \text { StudFacRatio }_{i}+\alpha_{5} \text { lnExpStudent }{ }_{i} \\
& +\beta_{\text {Cost } N \text { etCost }} i j+\beta_{\text {Cost }^{2}} \text { NetCost }_{i j}^{2}+\beta_{G M} G M_{i j}+\beta_{G P} G P_{i j}+\beta_{J L} J L_{i j} \\
& +\beta_{\text {Fem } \text { Female }_{j}} * \text { Rank }_{i}+\beta_{\text {Min }} \text { Minority }_{j} * \text { Rank }_{i}+\beta_{\text {Min } \% \text { Minority }} * \% \text { Minority }_{i} \\
& +\beta_{Y r} Y r * \text { Rank }_{i}+\alpha_{Q 4}^{S A T} S A T_{j}^{Q 4} * \text { Rank }_{i}+\alpha_{Q 3}^{P I} \text { ParentInc. }_{j}^{Q 3} * \text { Cost }_{i}+\alpha_{Q 4}^{P I} \text { ParentInc. }_{j}^{Q 4} * \text { Cost }_{i} \\
& +\beta_{\text {Dist } \text { Distance }_{i j}}+\beta_{\text {Dist }^{2}} \text { Distance }_{i j}^{2}+\sum_{k=1}^{77} \gamma_{k} \text { School }_{k}+\varepsilon_{i j}
\end{aligned}
$$

In equation 2 the variables GM, GP, and JL are defined as: GM=Grant/Merit only, $\mathrm{GP}=\mathrm{Grant} /$ Merit plus Job or Loan, and $\mathrm{JL}=\mathrm{Job}$ and/or Loan only package. The USNWR ranking enters the equation nonlinearly, to allow its impact to change as you move down the scale, and expenditures per student enters log-linearly. We allow for differing impacts across quartiles of the SAT distribution and test for differences across parental income quartiles. We found differences across income quartiles in sensitivity to cost but not to the USNWR rankings. The income quartiles are defined using the entire Colgate acceptance pool in each year. The estimation for the full-pay students is similar, with the exception that the financial aid and parental income variables are omitted, and there is an additional variable that captures the effect of whether a merit aid offer was extended. 


\section{Results}

Equation 2 is estimated for aided and full-pay applicants separately. The full-pay model is a subset of the aided model described above, as there is no financial aid packaging information to include and the parental income information is not available for the full-pay applicants. In the full-pay sample there were no differences in sensitivity to the USNWR rank by SAT quartiles, so we have omitted this variable. We have also included in the full-pay specification an interaction term of a merit aid offer and a top 25 ranking instead of the broader aid packaging term ${ }^{10}$. Finally, the set of school fixed effects for the aided sample ( 77 schools) is slightly different from the set for the full-pay students ( 75 schools). This is because of the different frequencies of top 40 schools in each group's choice set. Table 2 contains the parameter estimates from the conditional logit model for both the financial aid and the full-pay samples.

*********************** Include Table 2 Here

$* * * * * * * * * * * * * * * * * * * * * * *$

Across both estimations the influence of the USNWR rank on school choice is important and the effect is different as the rank worsens. This result is robust to controlling for the other objective measures of quality. It is also interesting to note that the full-pay sample is more sensitive to the rankings as evidenced by the larger coefficient estimates. The USNWR influence on school choice is somewhat different across aided students from different SAT quartiles. The rankings are slightly less important to students in the highest SAT quartile in the aided sample; however, there was no difference in the full-pay sample across SAT quartiles. Minorities are sensitive to the existing minority population of the school and full-pay minorities are more than twice as sensitive as their aided counterparts. In the aided sample women are slightly less responsive to rank differences than men and in the full-pay sample the school choice of minorities are less responsive to rank differences than non-minorities. Finally, in the aided sample the USNWR ranking itself has become more important to school choice over time.

The net cost of a school is found to be an important factor in school choice in both the aided sample but not for full-pays. In addition to the overall influence of net cost, we find consistent

\footnotetext{
${ }^{10}$ Merit Aid from any school was initially included and had no correlation with college choice, so we interact it with a top 25 ranking to test whether the proliferation of merit packages from higher-ranked schools systematically influences the matriculation decision in our sample.
} 
correlations between aid packaging and matriculation, suggesting that students are acting rationally in response to aid package offers. Full-packaging (grant/merit plus jobs and/or loans) is preferred to grants-only packaging, and both are preferred to job/loan only packaging. As expected, all these packages are preferred to no aid package. We collapsed the grant and merit categories for the aided students because there was no statistical difference in the estimates between them. The results from our estimation suggest that merit aid is not a tool available to administrators to lure high-income high-ability students away from the most prestigious and highly-ranked institutions. This is an interesting area for further work since merit aid for preferred groups has become a more common tool in the admissions process in recent years. We also find evidence that the distance from home is not a factor for students in either sample, although it is likely that this effect is partially being captured in the individual school fixed effects. Expenditures per student is correlated with matriculation across both samples, with students preferring schools that spend more (-or are wealthier). There is weak evidence that student-faculty ratio is correlated in the aided sample, although in the opposite direction as one would expect, and it is not correlated in the full-pay sample.

The coefficients estimated above are important in determining the overall performance and consistency of the model; however, a key measure of the importance of a change in a school's USNWR rankings is its impact on yield. Monks and Ehrenberg (1999) use aggregate data and are able to estimate the impact of a change in rank on a school's yield. Because the fitted value in our conditional logit is a predicted probability of matriculation, marginal effects or partial probability estimates give insight into the expected change in probability of attendance resulting from a one-unit change in an independent variable. Therefore we estimate the relative importance of the effects highlighted above by evaluating the partial probabilities for each student and averaging them over the sample for the variables of interest. These results are contained in Table 3.

$* * * * * * * * * * * * * * * * * * * * * * * \quad$ Include Table 3 Here

The results of the overall influence of the USNWR rankings are striking. Aided students looking at schools in the top 20 are predicted to experience about a .15 percentage point change in probability of attendance for every 1 place difference in their rank. This effect drops to about 
.10 and then lower for schools in the 20-40 range. The effect is much larger for full-pays, where rank differences in the top 20 are related to a .45 percentage point change per rank, with the effect leveling off around .35 as you reach a 40 point difference. These results for full-pay students are an order larger than those estimated by Monks and Ehrenberg (1999). However, their results (-.17) are quite close to our estimates for aided students. Figures 1 and 2 illustrate the relative influence of rankings and cost between the aided and full-pay samples. In Figure 1 the influence of a difference between two schools' USNWR rank is graphed against the estimated difference in probability of attending the worse ranked of the two schools. For example, the average aided student is about 1.6 percentage points less likely to attend a school ranked $10^{\text {th }}$ vs. a school ranked $1^{\text {st }}$. This is in contrast to the average full-pay student who is about 4.7 percentage points less likely to make that choice.

$* * * * * * * * * * * * * * * * * * * * * * *$ Include Figure 1 Here

The sensitivity difference to net cost between the different income quartiles of aided students is illustrated in Figure 2. It shows the lower probability of attendance with increasing cost differences between two schools. The results of our model suggest that for an aided student with below median family income, a change from no difference to a $\$ 1,000$ difference in cost (all else equal) will lower the average probability of attendance by about 3 percentage points. For those in the $3^{\text {rd }}$ and $4^{\text {th }}$ quartile that sensitivity drops to 2 and 1.5 percentage points respectively. These estimates for our aided sample should be viewed with some caution given the caveat about the measurement error in the aided net cost variable discussed above. Figure 2 illustrates these tradeoffs up to a cost difference of $\$ 4,000$.

$* * * * * * * * * * * * * * * * * * * * * * *$ Include Figure 2 Here

$* * * * * * * * * * * * * * * * * * * * * * *$

Finally, most of the school fixed effects estimates are statistically significant and take the expected sign. They are presented in Table 4 in order of average rank over the decade of the sample.

*********************** Include Table 4 Here

$* * * * * * * * * * * * * * * * * * * * * * *$ 
A few regularities are evident from these estimates. First, full-pay fixed effects are almost always significantly greater than their aided counterparts. As expected, wealthier students place more emphasis on the prestige, quality, physical plant, and other unchanging characteristics that these estimates measure. Second, the magnitude of the fixed effect estimates declines as the rank of the school declines. As a group, it is not surprising that the Ivy League schools have the highest desirability in this sample, especially among the full-pay students. However, across both samples as you move out of the top 20 schools in average rank the fixed effects largely disappear. These effects are measured relative to schools not categorized as NU or NLA schools, along with a few schools that are but did not have enough data in the sample. There is another interesting characteristic of this sample that is evident from these estimations. Even though Colgate is classified as a National Liberal Arts college, the applicant pool appears to have a slight preference for larger, often urban institutions. The first piece of evidence for this is the result from above where higher student-faculty ratios are associated with higher probabilities of attendance. It is more evident in the magnitude and significance of the fixed effect estimates. An example of this in the top 20 is the difference between Colby and Notre Dame or University of Virginia's estimates. The bigger schools are often twice as desirable as Colby (all else in the model equal). As you move into schools ranked in the 20s and 30s, many of the smaller schools fixed effects are not different from zero. However, the desirability of places such as

Georgetown, Tufts, Wake Forest, and Boston College are significantly higher than their national liberal arts counterparts in the rankings. These results suggest that schools are not necessarily competing for high-ability students only against other schools like themselves. In the case of Colgate, a large (by liberal arts standards) school in the liberal arts category is competing against much larger schools in the National University category. The magnitude of these estimates shows that there are strong preferences for larger schools within the Colgate admitted applicant pool.

\section{Conclusions}

In this paper we investigate the influence of the USNWR rankings on the college choice of high-ability high school seniors conditional on the fact that they've been accepted to the school. Using a micro dataset of school choice from the Colgate University population of admitted 
students between 1995 and 2004 we estimate a conditional logit model where school choice is modeled as a function of the USNWR rank of each school along with other school and individual characteristics. Because Colgate's applicant and admit populations cover a broad range of highability students with choices of highly and less-highly selective colleges and universities, our results are based upon choices made from a wide range of schools. The schools in our applicant choice set cover those ranked from first to fiftieth in both the liberal arts and national university categories. It also includes schools that are unranked and some regional colleges and universities. With such a wide range of schools represented we feel that our results are general to both high-ability students and highly selective schools.

The importance of the USNWR rankings is a hotly debated topic on college campuses across the country. Will efforts to raise a school's rank increase their yield of the best students and improve their student profile? Our results suggest that there is a benefit to a positive change in a school's USNWR rank. We find that full-pay applicants are more likely to attend a school that is higher ranked by even a few places. Aided applicants are less responsive, but still systematically prefer higher-ranked schools. More importantly, these preferences for the USNWR rank are independent of other measures of quality (student-faculty ratio and expenditures per student), and estimates of school fixed effects themselves. This would be less distressing if the USNWR rank were a widely accepted measure of quality. However, the measures included as components of the rank, especially the weights attached to those components, are somewhat arbitrarily chosen in terms of being measures of educational quality. There are differences in magnitude of the influence of the USNWR ranking across race and gender, but these are smaller than the overall influence of the rankings themselves. Also important in our results is the finding that minorities are more likely to attend schools that have larger minority populations, suggesting that programs or initiatives to diversify the student population make it easier to attract and yield diversity in the future. Our results suggest that admissions officers and other administrators concerned with the quality of incoming classes have reason to be concerned about their school's USNWR rank because it is shown here to be an important factor in the matriculation decision of high-ability students. 


\section{References}

Avery, Christopher and Caroline Hoxby (2003) "Do and Should Financial Aid Packages Affect Students' College Choices?” NBER Working Paper \#9482, February.

College Board (various years) Annual Survey of Colleges of the College Board and Data Base, 1995-1996 through 2004-2005. Copyright (C) College Entrance Examination Board. All rights reserved.

Ehrenberg, Ronald and Daniel Sherman (1984) "Optimal Financial Aid Policies for a Selective University,” Journal of Human Resources, Vol.19, No.2, pp.202-230.

Friedman, Alex and Kevin Rask (2004) "The Real Influence of the Main Components of the USNWR Rankings on Changing a School's Rank," Unpublished manuscript, Colgate University Department of Economics.

McPherson, Michael and Morton Schapiro (1991) "Does Student Aid Affect College Enrollment? New Evidence on a Persistent Controversy," American Economic Review, Vol.81, No.1, March, pp.309-318.

Monks, James and Ronald Ehrenberg (1999) “U.S. News and World Report's College Rankings: Why Do They Matter," Change, Vol. 31, No.6, November/December, pp.42-51.

Moore, Robert, A.H. Studenmund, and Thomas Slobko (1991) "The Effect of the Financial Aid Package on the Choice of a Selective College," Economics of Education Review, Vol.10, No.4, pp. 311-321.

Parker, Jeffrey and Jeffrey Summers (1993) “Tuition and Enrollment Yield at Selective Liberal Arts Colleges," Economics of Education Review, Vol.12, No.4, pp. 311-324.

Spies, Richard (1973) "The Future of Private Colleges: The Effect of Rising Costs on College Choice,” manuscript, Industrial Relations Section, Princeton University, Princeton, NJ.

Spies, Richard (1978) "The Effect of Rising Costs on College Choice: A Study of the Application Decisions of High-Ability Students," research report, College Entrance Examination Board, Princeton, NJ.

Webster, Thomas (2001a) "A Principal Component Analysis of the U.S. News \& World Report Tier Rankings of Colleges and Universities," Economics of Education Review, Vol.20, No.3, June, pp.235-244.

Webster, Thomas (2001b) "A Principal Components Analysis of the U.S. News \& World Report Tier Rankings of National Liberal Arts Colleges," Journal of Applied Business Research, Vol.17, No.1, Winter, pp.39-54. 
Weiler, William (1996) "Factors Influencing the Matriculation Choices of High Ability Students," Economics of Education Review, Vol. 15, no. 1, pp.23-36. 
Table 1: Sample Student and School Descriptive Statistics

\begin{tabular}{|c|c|c|c|c|c|}
\hline \multicolumn{3}{|c|}{--- Financial Aid Sample --- } & \multicolumn{3}{|c|}{--- Full-Pay Sample --- } \\
\hline Variable & & Value & Variable & & Value \\
\hline Combined SAT & & & Combined SAT & & \\
\hline $75^{\text {th }}$ Percentile & & 1420 & $75^{\text {th }}$ Percentile & & 1410 \\
\hline $50^{\text {th }}$ Percentile & & 1350 & $50^{\text {th }}$ Percentile & & 1350 \\
\hline $25^{\text {th }}$ Percentile & & 1290 & $25^{\text {th }}$ Percentile & & 1290 \\
\hline Proportion of Women & & $57.5 \%$ & Proportion of Women & & $53.6 \%$ \\
\hline Proportion of Minorities & & $19.3 \%$ & Proportion of Minorities & & $7.8 \%$ \\
\hline $\begin{array}{l}\text { Most Frequent Schools in } \\
\text { Aided Choice Set }\end{array}$ & Freq. & $\begin{array}{c}\text { Average } \\
\text { USNWR Rank }\end{array}$ & $\begin{array}{l}\text { Most Frequent Schools in } \\
\text { Full-Pay Choice Set }\end{array}$ & Freq. & $\begin{array}{c}\text { Average } \\
\text { USNWR Rank }\end{array}$ \\
\hline Univ. Rochester & 356 & 32.9 & Colby College & 388 & 18.8 \\
\hline Cornell Univ. & 327 & 12.1 & Middlebury College & 353 & 7.7 \\
\hline Bucknell Univ. & 298 & 28.7 & Bucknell Univ. & 285 & 28.5 \\
\hline Boston College & 262 & 37.9 & Boston College & 269 & 38.0 \\
\hline Hamilton College & 238 & 21.9 & Cornell Univ. & 246 & 12.4 \\
\hline Middlebury College & 194 & 7.6 & Tufts Univ. & 190 & 27.7 \\
\hline Holy Cross & 158 & 27.5 & Univ. of Michigan & 184 & 36.0 \\
\hline Tufts Univ. & 154 & 27.1 & Vanderbilt Univ. & 179 & 20.2 \\
\hline Boston Univ. & 149 & 80.6 & Georgetown Univ. & 171 & 22.4 \\
\hline Colby College & 148 & 19.0 & Bates College & 167 & 20.7 \\
\hline New York Univ. & 143 & 34.9 & Bowdoin College & 164 & 6.8 \\
\hline SUNY Binghamton & 134 & 76.6 & Trinity College, Conn. & 155 & 38.6 \\
\hline Dartmouth College & 133 & 8.0 & Hamilton College & 152 & 20.3 \\
\hline Lafayette College & 116 & 33.6 & Washington Univ. & 143 & 33.0 \\
\hline Union College, NY & 116 & 34.4 & Emory Univ. & 138 & 15.9 \\
\hline Vassar College & 114 & 15.8 & Dartmouth College & 125 & 8.0 \\
\hline Lehigh Univ. & 105 & 36.9 & Holy Cross & 118 & 27.5 \\
\hline SUNY Geneseo & 104 & 79.5 & Wesleyan Univ. & 100 & 11.2 \\
\hline Williams College & 103 & 2.6 & Williams College & 100 & 2.6 \\
\hline Bowdoin College & 97 & 7.1 & Vassar College & 91 & 15.5 \\
\hline Syracuse Univ. & 97 & 65.6 & Univ. of Pennsylvania & 88 & 8.1 \\
\hline Wesleyan Univ. & 97 & 10.9 & Univ. of Richmond & 86 & 30.3 \\
\hline Franklin \& Marshall & 94 & 33.4 & Lafayette College & 83 & 34.3 \\
\hline William \& Mary & 92 & 33.2 & Brown Univ. & 81 & 11.8 \\
\hline Georgetown Univ. & 91 & 22.6 & Connecticut College & 78 & 27.1 \\
\hline Univ. of Notre Dame & 91 & 18.5 & Union College, NY & 74 & 34.0 \\
\hline
\end{tabular}


Table 2: Conditional Logit Estimation Results: Parameter Estimates

\begin{tabular}{|c|c|c|c|}
\hline \multicolumn{2}{|c|}{--- Financial Aid Sample --- } & \multicolumn{2}{|c|}{--- Full-Pay Sample --- } \\
\hline Variable & Coefficient & Variable & Coefficient \\
\hline Student-Faculty Ratio & $0.0149^{*}$ & Student-Faculty Ratio & 0.0198 \\
\hline lnExpenditures/Student & $0.4443^{* * *}$ & lnExpenditures/Student & $0.5643^{* *}$ \\
\hline USNWR Rank & $-0.0077^{* * *}$ & USNWR Rank & $-0.0254^{* * *}$ \\
\hline USNWR Rank $^{2}$ & $0.00003^{* * *}$ & USNWR Rank $^{2}$ & $0.0001^{* * *}$ \\
\hline Net Cost (thousands '05 \$) & $-0.1279^{* * *}$ & Net Cost (thousands '05 \$) & 0.0100 \\
\hline Net Cost $^{2}$ (thousands '05 \$) & 0.0007 & Net Cost ${ }^{2}$ (thousands '05 \$) & -0.0004 \\
\hline Grant/Merit Only & $0.9753^{* * *}$ & Merit*Top25 & -0.0386 \\
\hline Grant/Merit Plus & $1.3094^{* * *}$ & & \\
\hline Job and/or Loan Only & $0.5520^{* * *}$ & & \\
\hline Female*USNWR Rank & $0.0044^{* * *}$ & Female*USNWR Rank & 0.0018 \\
\hline Minority*USNWR Rank & -0.0022 & Minority*USNWR Rank & $0.0063^{*}$ \\
\hline Minority*\%Minority & $0.0153^{* * *}$ & Minority*\%Minority & $0.0359^{* * *}$ \\
\hline Year*USNWR Rank & $-0.0008^{* * *}$ & Year*USNWR Rank & 0.00004 \\
\hline Size & $-0.00001^{*}$ & Size & 0.00001 \\
\hline SATQ4*USNWR Rank & $0.0030^{*}$ & & \\
\hline Parent IncomeQ3*Net Cost & $0.0406^{* *}$ & & \\
\hline Parent IncomeQ4*Net Cost & $0.0587^{* * *}$ & & \\
\hline Distance from Home & -0.0002 & Distance from Home & -0.0003 \\
\hline Distance from Home ${ }^{2}$ & 0.0000001 & Distance from Home ${ }^{2}$ & 0.0000001 \\
\hline
\end{tabular}

Note: $* * *=\mathrm{p}$-value $<.01, * *=\mathrm{p}$-value $<.05, *=\mathrm{p}$-value $<.10$ 
Table 3: Partial Probabilities (x100) of College Choice Estimates

\begin{tabular}{|c|c|c|c|}
\hline \multicolumn{2}{|c|}{--- Financial Aid Sample --- } & \multicolumn{2}{|c|}{--- Full-Pay Sample --- } \\
\hline Variable & Marginal Effect & Variable & Marginal Effect \\
\hline Student-Faculty Ratio & 0.360 & Student-Faculty Ratio & --- \\
\hline lnExpenditures/Student & 9.705 & lnExpenditures/Student & 12.16 \\
\hline USNWR Rank & -0.168 & USNWR Rank & -0.490 \\
\hline USNWR Rank ${ }^{2}$ & 0.001 & USNWR Rank $^{2}$ & 0.002 \\
\hline Net Cost (thousands '05 \$) & -2.849 & Net Cost (thousands '05 \$) & --- \\
\hline Net Cost $^{2}$ (thousands '05 \$) & --- & Net Cost $^{2}$ (thousands '05 \$) & --- \\
\hline Grant/Merit Only & 19.91 & Merit*Top25 & \\
\hline Grant/Merit Plus & 26.97 & & \\
\hline Job and/or Loan Only & 11.43 & & \\
\hline Female*USNWR Rank & 0.087 & Female*USNWR Rank & --- \\
\hline Minority*USNWR Rank & --- & Minority*USNWR Rank & 0.134 \\
\hline Minority*\%Minority & 0.311 & Minority*\%Minority & 0.706 \\
\hline Year*USNWR Rank & -0.013 & Year*USNWR Rank & --- \\
\hline Size & --- & Size & --- \\
\hline SATQ4*USNWR Rank & 0.053 & & \\
\hline Parent IncomeQ $3 *$ Net Cost & 0.849 & & \\
\hline Parent IncomeQ $4 *$ Net Cost & 1.271 & & \\
\hline Distance from Home & --- & Distance from Home & --- \\
\hline Distance from Home ${ }^{2}$ & --- & Distance from Home ${ }^{2}$ & --- \\
\hline
\end{tabular}

Note: Marginal effects are evaluated at each observation and averaged over the sample. 
Table 4: Conditional Logit Estimation Results: School Fixed effect Estimates ( $\gamma$ 's)

\begin{tabular}{|c|c|c|c|c|c|}
\hline Avg. Rank 1-20 & Aided & Full-Pay & Avg. Rank 20-40 & Aided & Full-Pay \\
\hline Amherst & $1.72^{* * * *}$ & $2.75^{* * *}$ & Bates & 0.32 & $0.72^{* * * *}$ \\
\hline Princeton & $1.92^{* * *}$ & $3.25^{* * *}$ & Hamilton & 0.02 & $-.61^{* *}$ \\
\hline Harvard & $1.88^{* * *}$ & $3.24^{* * *}$ & U.C. Berkeley & 0.49 & $1.25^{* * *}$ \\
\hline Swarthmore & $1.93^{* * *}$ & $1.09^{* * *}$ & Trinity & $-0.83^{* *}$ & 0.11 \\
\hline Yale & $2.48^{* * *}$ & $3.24^{* * *}$ & Georgetown & $1.54^{* * *}$ & $2.60^{* * *}$ \\
\hline Williams & $1.82^{* * *}$ & $2.68^{* * *}$ & Oberlin & -0.14 & 0.50 \\
\hline Wellesley & $1.43^{* * *}$ & $2.39^{* * *}$ & Carnegie Mellon & 0.03 & 0.75 \\
\hline MIT & $1.95^{* *}$ & $\mathrm{~N} / \mathrm{A}$ & Michigan & 0.00 & 0.26 \\
\hline Stanford & $2.05^{* * *}$ & $2.64^{* * *}$ & Tufts & $0.88^{* * *}$ & $1.50^{* * *}$ \\
\hline Pomona & $1.54^{* * *}$ & $2.41^{* * *}$ & U. South & $\mathrm{N} / \mathrm{A}$ & $1.41^{*}$ \\
\hline Haverford & $1.20^{* * *}$ & $1.72^{* * *}$ & UCLA & $1.00^{*}$ & -0.16 \\
\hline Bowdoin & $1.24^{* * *}$ & $1.81^{* * *}$ & UNC & 0.76 & $1.21^{* *}$ \\
\hline Middlebury & $1.30^{* * *}$ & $2.23^{* * *}$ & Macalester & 0.36 & 0.41 \\
\hline Carleton & $0.90^{* *}$ & 0.54 & Colorado College & 0.19 & 0.20 \\
\hline U. Pennsylvania & $1.03^{* * *}$ & $2.04^{* * *}$ & Connecticut College & -0.39 & 0.11 \\
\hline Dartmouth & $1.84^{* * *}$ & $3.08^{* * *}$ & Wake Forest & 0.48 & $0.75^{* *}$ \\
\hline Columbia & $1.53^{* * *}$ & $1.55^{* * *}$ & Holy Cross & 0.24 & $0.74^{* * *}$ \\
\hline Davidson & $1.60^{* * *}$ & $1.82^{* * *}$ & Barnard & $1.24^{* * *}$ & $2.46^{* * *}$ \\
\hline Wesleyan & $0.93^{* * *}$ & $1.72^{* * *}$ & Bucknell & 0.08 & -0.03 \\
\hline Northwestern & $1.21^{* * *}$ & $1.90^{* * *}$ & Brandeis & 0.10 & 0.16 \\
\hline U. Chicago & $1.32^{* * *}$ & $1.47^{* * *}$ & William \& Mary & $1.34^{* * *}$ & $2.06^{* * *}$ \\
\hline Cornell & $1.34^{* * *}$ & $1.97^{* * *}$ & Kenyon & 0.50 & $0.74^{*}$ \\
\hline Brown & $1.81^{* * *}$ & $3.09^{* * *}$ & Rochester & $-0.67^{* * *}$ & $-1.00^{*}$ \\
\hline Smith & $1.49^{* * *}$ & 0.66 & Lafayette & -0.22 & -0.54 \\
\hline Washington \& Lee & $1.19^{* * *}$ & $1.61^{* * *}$ & Franklin \& Marshall & -0.44 & 0.07 \\
\hline Grinnell & -0.18 & 0.22 & UCSD & -0.58 & -0.20 \\
\hline Claremont & $1.50^{* *}$ & $1.37^{* * *}$ & NYU & $0.39^{*}$ & 0.35 \\
\hline Johns Hopkins & $0.81^{* *}$ & $1.14^{* *}$ & Union & -0.04 & -0.76 \\
\hline Bryn Mawr & $0.97^{* *}$ & $1.23^{*}$ & U.W.-Madison & -0.53 & -0.65 \\
\hline Rice & $1.27^{* *}$ & 1.61 & Lehigh & $-0.60^{* *}$ & 0.06 \\
\hline Vassar & $0.58^{* *}$ & $1.50^{* * *}$ & Whitman & 0.33 & 0.57 \\
\hline Wash. U. - St. Louis & 0.42 & 0.39 & Case Western & -0.25 & N/A \\
\hline Emory & 0.45 & 0.44 & Bard & 0.46 & 0.84 \\
\hline Colgate & $1.11^{* * *}$ & $1.32^{* * *}$ & USC & 0.69 & 0.03 \\
\hline Notre Dame & $1.65^{* * *}$ & $2.87^{* * *}$ & Boston College & $1.03^{* * *}$ & $1.44^{* * *}$ \\
\hline Colby & $0.56^{* * *}$ & $0.95^{* * *}$ & Depauw & -0.51 & $\mathrm{~N} / \mathrm{A}$ \\
\hline Vanderbilt & $0.67^{* *}$ & 0.46 & Occidental & -0.22 & 2.04 \\
\hline Mount Holyoke & 0.63 & 0.40 & Tulane & -0.03 & -1.30 \\
\hline U. Virginia & $1.17^{* * *}$ & $2.64^{* * *}$ & Georgia Tech & -0.15 & 1.09 \\
\hline
\end{tabular}

Note: $* * *=\mathrm{p}$-value $<.01, * *=\mathrm{p}$-value $<.05, *=\mathrm{p}$-value $<.10$ 
Figure 1: USNWR Rank Differences vs. Probability of Attendance

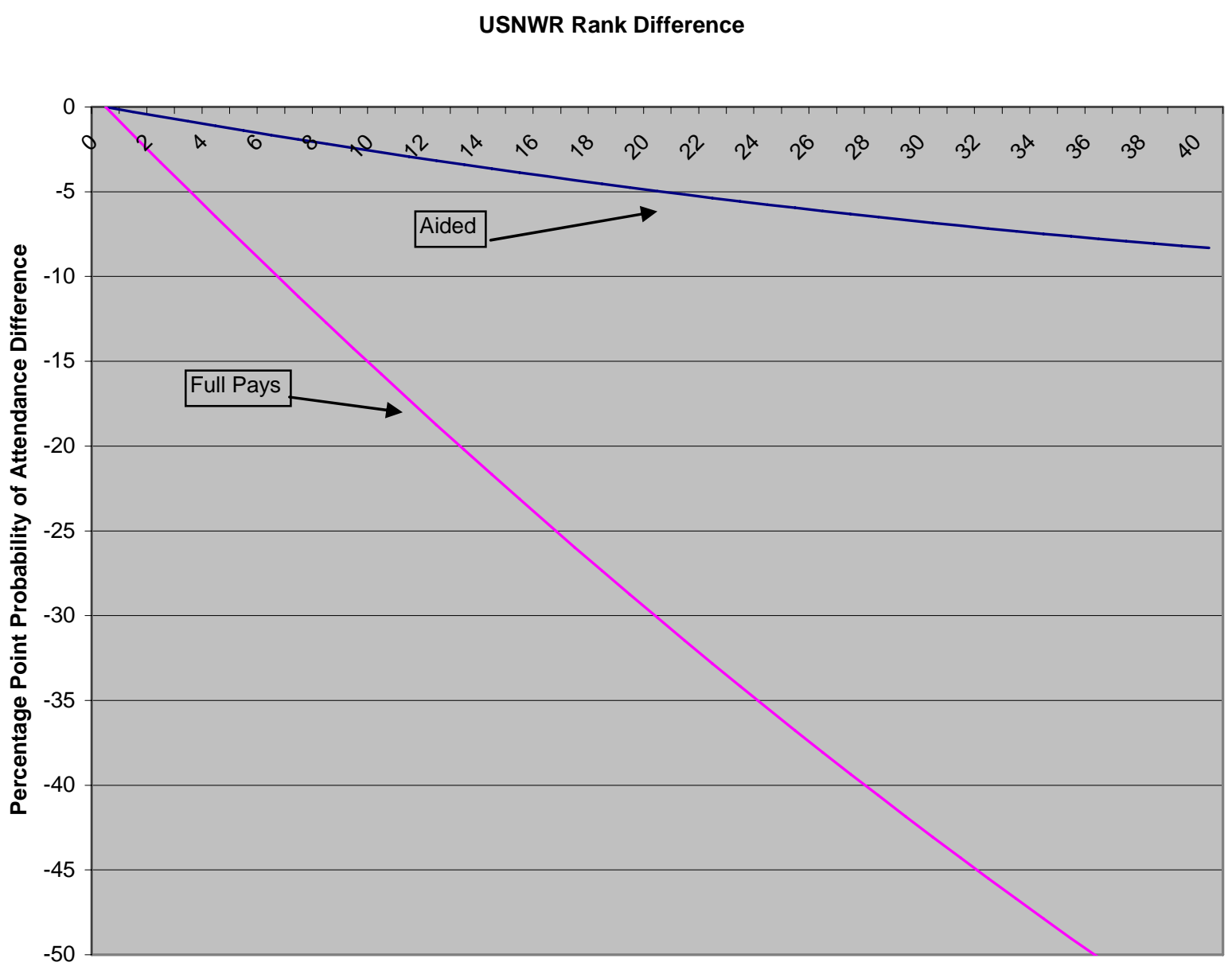


Figure 2: Net Cost Differences vs. Probability of Attendance

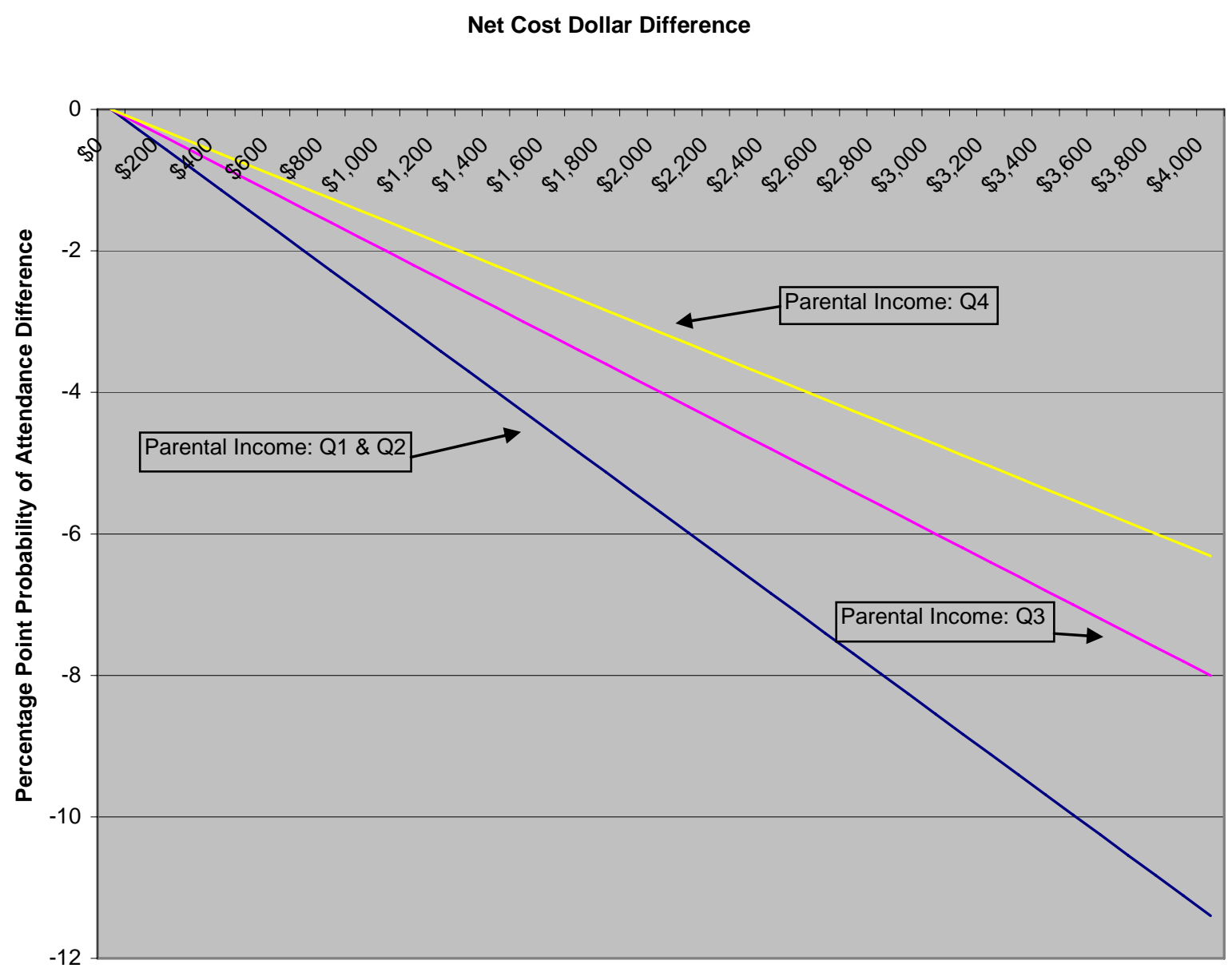

